\title{
The lysosomal/phagosomal membrane protein h-lamp-1 is a target of the IgA1 protease of Neisseria gonorrhoeae
}

\author{
Christof R. Hauck ${ }^{\mathrm{a}}$, Thomas F. Meyer ${ }^{\mathrm{a}, \mathrm{b}, *}$ \\ ${ }^{a}$ Max-Planck-Institut für Biologie, Abteilung Infektionsbiologie, Spemannstr. 34, 72076 Tübingen, Germany \\ ${ }^{\mathrm{b}}$ Max-Planck-Institut für Infektionsbiologie, Abteilung Molekulare Biologie, Monbijoustr. 2, 10117 Berlin, Germany
}

Received 17 January 1997; revised version received 4 February 1997

\begin{abstract}
Lysosomal/phagosomal membranes of mammalian cells are coated by highly conserved glycoproteins (lamps) that are thought to protect the membranes from degradation. Interestingly, we identified an amino acid sequence in human lamp-1 characteristic of a cleavage site for the Neisseria gonorrhoeae IgA1 protease. Furthermore, gonococci are detected in h-lamp-1-positive vacuoles after their uptake by professional phagocytes and epithelial cells. Here we demonstrate cleavage of glycosylated h-lamp-1 by the secreted gonococcal IgA1 protease. The cleavage was observed with h-lamp-1 purified from epithelial cells but not from professional phagocytes. The biological role of lamp-1 cleavage by the gonococcal protease is discussed.
\end{abstract}

Key words: Gonococci; IgA1 protease; Phagosome; Lysosomal membrane protein; h-lamp

\section{Introduction}

The genus Neisseria encompasses Gram-negative diplococcal bacteria that successfully colonise human mucosal tissues. Although most of them live as harmless commensals, two species, Neisseria gonorrhoeae and $N$. meningitidis, are the disease causing agents of gonorrhoea and bacterial meningitis, respectively [1]. One of the key features that distinguish pathogenic from non-pathogenic Neisseria is the secretion of an IgA1-specific serine protease (IgA1 protease) by gonococci and meningococci $[2,3]$. Despite the fact that the secretion of this protease seems not to be crucial for the initial colonisation of the urogenital mucosa and it appears not to be required for the adherence and the invasion of epithelial cells by $N$. gonorrhoeae in vitro [4], this enzyme apparently confers a selective advantage in vivo $[5,6]$.

Amongst different clinical isolates of $N$. gonorrhoeae and $N$. meningitidis, two subtypes of the protease have been found [7]. Both IgA1 protease forms possess a very similar proline-rich consensus cleavage sequence within the hinge region of human IgA1 that is deleted in IgA2 (see Fig. 1). In addition to human IgA1, this consensus sequence is detectable in several other human proteins, most of them cell surface proteins like CD8 where it was shown to be cleaved in a heterologous protein backbone $[10,11]$. Other potential target molecules, like synaptobrevin II, are restricted to defined intracellular compartments that may not naturally be accessible by gonococci [12]. Even though at first sight it seems unlikely that the $\operatorname{IgA} 1$ protease interacts with intracellular substrates, this bacterial enzyme could act within infected cells: pathogenic Neisseria

*Corresponding author. Fax: (49) (7071) 610379.

E-mail: sinfbio@mpib-tuebingen.mpg.de are known to invade different cell types in vitro and in vivo, where they could come into intimate contact with intracellular proteins. For example, the co-localisation between internalised bacteria and phagosomal proteins has already been documented for a long list of intracellular microorganisms [13-15].

In this paper we show that intracellular $N$. gonorrhoeae resides in the same compartment as the human lysosome/late endosome-associated membrane protein 1 (h-lamp-1) and that this membrane protein contains the consensus sequence for cleavage by the gonococcal IgA1 protease. In addition, we demonstrate that the secreted enzyme can be active in an acidic phagosomal micro-environment and that the IgA1 protease is capable of cleaving glycosylated h-lamp-1.

\section{Materials and methods}

\subsection{Cells and culture}

Chang human conjunctiva cells (ATCC CCL20.2) and RT112 human bladder carcinoma cells [16] were cultured as monolayers in DMEM medium supplemented with $10 \%$ fetal calf serum (FCS) at $37^{\circ} \mathrm{C}$ in $5 \% \mathrm{CO}_{2}$. The human myelomonocytic cell line JOSK-M and myelocytic HL60 cells, obtained from the German Collection for Microorganisms, Braunschweig (DSM ACC30 and DSM ACC3), were grown as suspensions in RPMI 1640 (Gibco BRL, Paisley, UK) supplemented with $10 \%$ FCS (Boehringer Mannheim, Germany), $2 \mathrm{mM}$ L-glutamine at $37^{\circ} \mathrm{C}, 5 \% \mathrm{CO}_{2}$. Cells were subcultured every 3-4 days. Prior to infection with gonococci, HL60 cells were differentiated in vitro by adding DMSO to a final concentration of $1.25 \%$ to the culture medium and incubating the cells for 5-7 days. Viability was determined prior to infection using trypan blue staining and in all cases was $>90 \%$.

\subsection{Bacteria}

The gonococcal variant MS11-N139 (B2.1; $\left.\mathrm{P}^{-} \mathrm{Opa}_{30}{ }^{+}\right)[17]$ is the progenitor of the strains used in this work. Strain N303 expressing $\mathrm{Opa}_{50}$ and strain N309 expressing $\mathrm{Opa}_{52}$ have been described [18]. The construction of the IgA1 protease-negative $N$. gonorrhoeae MS11 expressing $\mathrm{Opa}_{50}$, i.e. N876, was accomplished by transformation of strain N303 with pRB2 harbouring a kanamycin resistance cassette in the BglII site of the IgAl protease [19]. The successful knock-out of IgA1 protease expression and secretion was tested by immunoblotting of total bacterial lysates and culture supernatants (data not shown). All gonococci were grown on GC agar (Gibco BRL) supplemented with vitamins and corresponding antibiotics at $37^{\circ} \mathrm{C}$ under $5 \% \mathrm{CO}_{2}$ and subcultured daily.

\subsection{Infection with gonococci and gentamicin assay}

For infection, bacteria were taken from plates, suspended in PBS containing $1 \mathrm{mM} \mathrm{Ca}{ }^{2+}$ and $1 \mathrm{mM} \mathrm{Mg}^{2+}$ (PBS+) and washed by centrifugation at $500 \times \mathrm{g}$ for $5 \mathrm{~min}$. The optical density at $550 \mathrm{~nm}$ was determined in a Hach spectrophotometer (Hach, Coveland, $\mathrm{CO})$ and gonococci expressing $\mathrm{Opa}_{52}$ or $\mathrm{Opa}_{50}$ were added to suspended HL60 cells or to Chang cells growing on glass coverslips in 24 well plates (Nunc, Roskilde, Denmark) at a ratio of 30 bacteria per cell to start the infection. In the case of HL60 cells, non-ingested gonococci were separated from the cells $2 \mathrm{~h}$ after the start of the infection by repeated centrifugation at $150 \times g$ for $5 \mathrm{~min}$ and washing with PBS+. Cells were centrifuged on glass coverslips in 24 well plates 
and fixed with $3 \%$ paraformaldehyde. In the case of Chang cells, noninvasive bacteria were separated from cells $4 \mathrm{~h}$ after the start of the infection by repeated washing with PBS + and the cells were fixed in $3 \%$ paraformaldehyde for immunofluorescence staining.

For the gentamicin assay, Chang cells or RT112 cells were cultured in 24 well plates without coverslips, $1 \times 10^{7}$ bacteria of strains N303 or N876 were added to $2 \times 10^{5}$ target cells in DMEM supplemented with $10 \%$ FCS and $1 \mathrm{U}$ benzonase (Boehringer Mannheim, Germany) and the infection was allowed to proceed for $6 \mathrm{~h}$ (Chang cells) or $12 \mathrm{~h}$ (RT112 cells). Samples were washed three times with PBS+ and incubated for $1 \mathrm{~h}$ in DMEM, $10 \%$ FCS and $50 \mu \mathrm{g} / \mathrm{ml}$ gentamicin. After three washes with PBS+ the cells were lysed with $1 \%$ saponin in PBS+ for $10 \mathrm{~min}$ at $37^{\circ} \mathrm{C}$ and appropriate dilutions of the suspensions were plated on GC agar to determine the colony forming units.

\subsection{Immunofluorescence staining}

Cells were fixed on glass coverslips for $30 \mathrm{~min}$ in 3\% paraformaldehyde in PBS+ at room temperature. After three washes with PBS+, cells were incubated for $5 \mathrm{~min}$ in PBS+, $10 \% \mathrm{FCS}, 0.2 \%$ saponin in order to permeabilise the cells and block non-specific binding sites. Suitable dilutions of polyclonal rabbit $\alpha-N$. gonorrhoeae MS11 (1:200; AK92) and monoclonal mouse $\alpha$-h-lamp-1 (1:50; clone H4A3; obtained from DSHB, University of Iowa) were added in PBS+, $10 \%$ FCS, $0.2 \%$ saponin for $1 \mathrm{~h}$ at room temperature. Samples were washed twice with PBS+, blocked again for $5 \mathrm{~min}$ and incubated with FITC-conjugated goat $\alpha$-rabbit and TexasRed-conjugated goat $\alpha$-mouse antibodies (Sigma ImmunoChemicals, St. Louis, MO) for 45 min at room temperature. After three washes with PBS+, coverslips were mounted in glycerol medium (Sigma ImmunoChemicals), sealed with nail polish, and viewed with a Leica TCS 4D confocal laser scanning microscope (Leica Lasertechnik, Heidelberg, Germany) equipped with an argon/krypton mixed gas laser. Images were taken serially using appropriate excitation and emission filters for the used fluorescent dyes. The corresponding images were digitally processed with Photoshop 3.0 (Adobe Systems, Mountain View, CA).

\subsection{Preparation of recombinant IgAl protease and demonstration of enzyme activity}

IgA1 protease of $N$. gonorrhoeae MS11 was prepared as described [10]. $2 \mu \mathrm{g}$ of immunoglobulin A1 isolated from human sputum (Sigma Chemicals) was incubated with $2 \mu 1$ of the purified recombinant IgA1 protease $(50 \mathrm{ng} / \mu \mathrm{l})$ in a total volume of $30 \mu \mathrm{l}$ for $1 \mathrm{~h}$ at $37^{\circ} \mathrm{C}$ using different buffers: $50 \mathrm{mM}$ sodium citrate, $10 \mathrm{mM} \mathrm{NaCl}$ adjusted to $\mathrm{pH}$ 4.5 or 5 , or $50 \mathrm{mM}$ sodium phosphate, $10 \mathrm{mM} \mathrm{NaCl}$ adjusted to $\mathrm{pH}$ $6,6.5,7$ or 7.5 . The reactions were stopped by the addition of $7 \mu 1$ $5 \times$ SDS sample buffer, $5 \% \beta$-mercaptoethanol and the proteins were separated by SDS electrophoresis on $12.5 \%$ polyacrylamide gels. Protein bands were visualised by silver staining.

\subsection{Immunoprecipitation of h-lamp-1 and cleavage with recombinant} IgA1 protease

Prior to immunoprecipitation, cells were labelled metabolically. The cells were washed twice in methionine-free RPMI 1640 and incubated for $30 \mathrm{~min}$ in methionine-free medium at $37^{\circ} \mathrm{C}$. Cells were adjusted to $2 \times 10^{7}$ cells $/ \mathrm{ml}$ and incubated for $30 \mathrm{~min}$ at $37^{\circ} \mathrm{C}$ in methionine-free RPMI 1640 supplemented with $500 \mu \mathrm{Ci} / \mathrm{ml}\left[{ }^{35}\right.$ S]methionine (Amersham Buchler, Braunschweig, Germany). Following the pulse, cells were diluted 20 times with RPMI 1640 containing non-radioactive methionine, washed once and adjusted to $2 \times 10^{6}$ cells $/ \mathrm{ml}$ with RPMI $1640,10 \%$ FCS. After chase periods ranging from 0 to 240 $\mathrm{min}, 2 \mathrm{ml}$ of the suspension was pelleted and the cells were lysed in 25 volumes of NP-40 lysis buffer $(50 \mathrm{mM}$ Tris- $\mathrm{HCl}, 0.15 \mathrm{M} \mathrm{NaCl}, 5 \mathrm{mM}$ EDTA, $0.5 \%$ NP-40, $5 \mu \mathrm{g} / \mathrm{ml}$ aprotinin, $5 \mu \mathrm{g} / \mathrm{ml}$ leupeptin, $1 \mathrm{mM}$ PMSF, $\mathrm{pH}$ adjusted to 7.5 at $4^{\circ} \mathrm{C}$ ) on ice for $30 \mathrm{~min}$. Lysates were centrifuged at $13000 \mathrm{rpm}$ for $30 \mathrm{~min}$ at $4^{\circ} \mathrm{C}$ and the supernatants transferred to $1.5 \mathrm{ml}$ Eppendorf reaction tubes. $80 \mu \mathrm{l}$ monoclonal mouse $\alpha$-h-lamp-1 (clone $\mathrm{H} 4 \mathrm{~A} 3$; $\mathrm{IgG}_{1}$ ) or $80 \mu \mathrm{l}$ of an isotype matched control antibody (mouse $\alpha$-canine E-cadherin; clone $\operatorname{rr} 1 ; \operatorname{IgG}_{1}$; provided as hybridoma culture supernatant from DSHB, University of Iowa) was added, and samples were incubated on a rotating shaker at $4^{\circ} \mathrm{C}$ for $4 \mathrm{~h}$. After addition of $70 \mu \mathrm{l}$ protein G-Sepharose (1:6 slurry of protein G-Sepharose and NP-40 lysis buffer) (Sigma ImmunoChemicals), the samples were rotated for another $2 \mathrm{~h}$ at $4^{\circ} \mathrm{C}$. Immunoprecipitates were collected by centrifugation at $4000 \mathrm{rpm}, 3$ min at $4^{\circ} \mathrm{C}$ and washed 4 times with NP-40 lysis buffer and once with PBS.
Precipitates were suspended in $50 \mu \mathrm{PBS}$, split into two tubes and incubated either with or without $3 \mu 1$ of recombinant gonococcal IgA1 protease $(50 \mathrm{ng} / \mu \mathrm{l})$ at $37^{\circ} \mathrm{C}$ for $4 \mathrm{~h}$. Reactions were stopped by the addition of $7 \mu 15 \times$ SDS sample buffer, $5 \% \beta$-mercaptoethanol and the proteins were resolved by SDS electrophoresis. After drying the gel, protein bands were detected by autoradiography or using a Phosphorimager (Fuji BAS Reader).

\section{Results}

\subsection{Internalised $N$. gonorrhoeae co-localises with lysosomal membrane proteins}

In order to determine the intracellular life style of $N$. gonorrhoeae, we set out to characterise the intracellular compartment occupied by these bacteria. Using double immunofluorescence staining and confocal laser scanning microscopy of infected cells, we were able to detect intracellular bacteria and eukaryotic marker proteins simultaneously. Apparently, in all human cell types tested, internalised gonococci co-localised with the lysosomal membrane proteins $\mathrm{h}$-lamp-1 and $\mathrm{h}$ lamp-2. These proteins are well-known constituents of late endosomal/lysosomal membranes and they are also characteristic markers for phagosomes in human professional phagocytes $[13,20]$. As can be clearly seen in Fig. 2, phagocytic human cells (HL60) engulfed numerous gonococci (Fig. 2A) and all intracellular bacteria were enclosed by h-lamp-1-positive vesicles (Fig. 2B). Additionally, although fewer bacteria were internalised by human epithelial cells (Chang conjunctiva), there was an obvious association of intracellular gonococci and h-lamp-1 (Fig. 2C,D). Use of monoclonal antibodies specific for h-lamp-2 resulted in the same staining pattern. Thus, both h-lamp proteins were present in Neisseria-containing vacuoles.

Especially in the epithelial cells, abundant small vesicles marked by h-lamp were visible within the cell, but they clearly differed in size from the $N$. gonorrhoeae-containing phagosomes. In epithelial as well as in phagocytic cells, single diplococci seemed to be enclosed by h-lamp-positive membranes.

\subsection{H-lamp-1 contains the IgA1 protease cleavage consensus sequence}

H-lamp molecules are known to possess an IgA1 globulinlike proline/serine/threonine-rich hinge region dividing their intra-luminal domain into two homologous subdomains [8,21]. Since the cleavage sites of the $\operatorname{IgA} 1$ protease of $N$. gonorrhoeae map within the IgA1 hinge region, we compared the sequence of the human IgAl globulin hinge region with the corresponding sequences of h-lamp molecules (Fig. 1). Studies on the processing of $\operatorname{IgA} 1$ as well as the $\operatorname{IgA} 1$ protease precursor led to a consensus sequence for cleavage by the

$$
\begin{aligned}
& \begin{array}{ll}
165 & \\
\text { h-lamp-1 } & \text { Q D R P P T T AP P } \quad \downarrow \text { A P P } \quad \downarrow \quad \text { S P SPSPVPKSPS }
\end{array}
\end{aligned}
$$

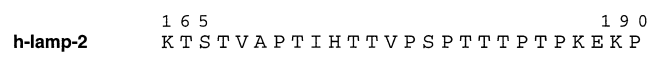

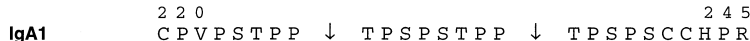

Fig. 1. Amino acid sequence comparison of the hinge-like regions of human lysosome-associated membrane proteins and the hinge region of human IgA1 globulin. The potential cleavage sites of the IgA1 protease of $N$. gonorrhoeae MS11 (PPXP, where X can represent alanine, threonine, or serine) are marked by an arrow $(\downarrow)$. The amino acid sequences are derived from Fukuda et al. [8] (h-lamp-1 and h-lamp-2) and Liu et al. [9] (IgA1 globulin), and the amino acids are numbered according to their position in the mature protein. 

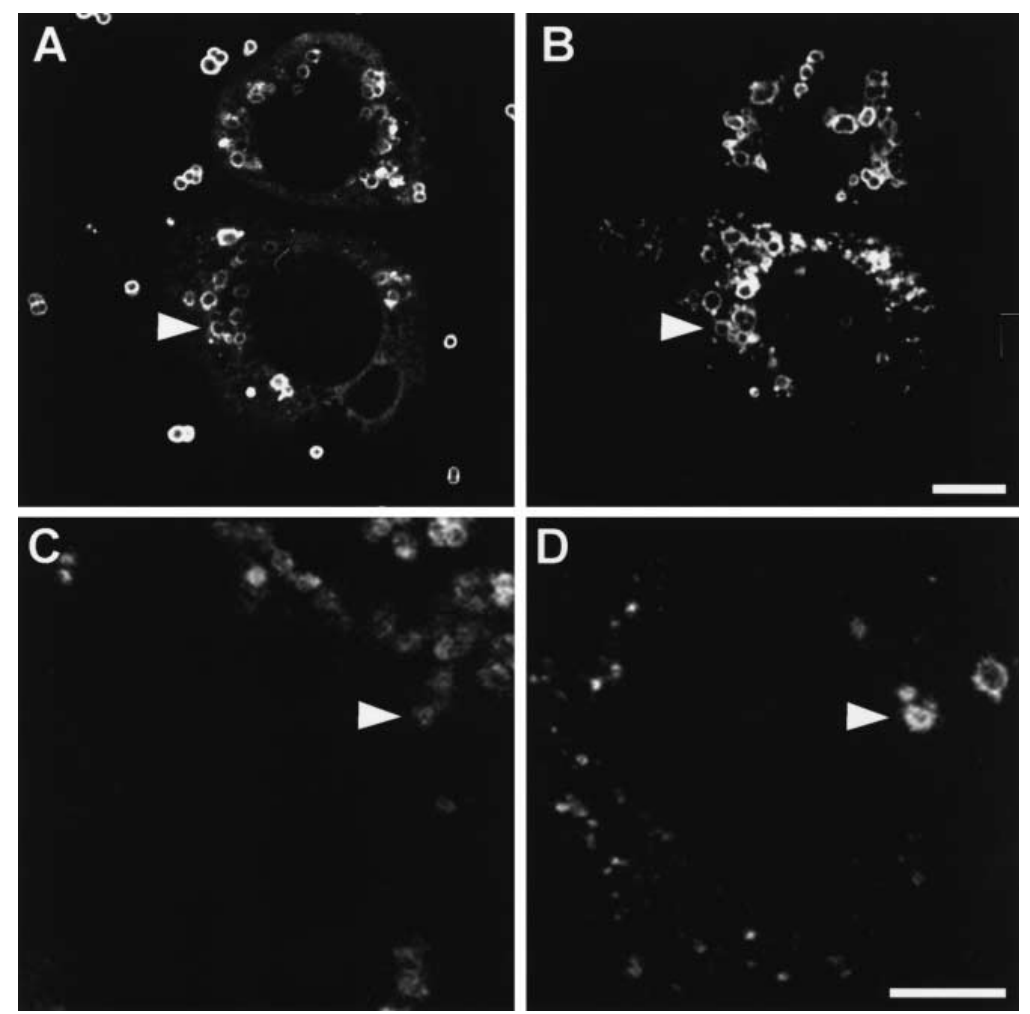

Fig. 2. Internalised $N$. gonorrhoeae co-localise with human lysosome-associated membrane proteins. Human phagocytic HL60 cells (A, B) and Chang conjunctiva cells (C, D) were infected with gonococci for $2 \mathrm{~h}$ or $4 \mathrm{~h}$, fixed with paraformaldehyde and stained simultaneously with a polyclonal rabbit $\alpha-N$. gonorrhoeae serum $(\mathrm{A}, \mathrm{C})$ and a monoclonal mouse $\alpha$-h-lamp-1 antibody (B, D). Confocal laser scanning microscopy revealed that intracellular bacteria (arrowheads; A, C) are tightly surrounded by h-lamp-1-coated membranes (arrowheads; B, D). The bars represent $5 \mu \mathrm{m}$.

gonococcal enzyme [2,10]. Interestingly, h-lamp-1 contains two sites fulfilling the requirements for cleavage by the IgA1 protease of $N$. gonorrhoeae within its luminal proline-rich sequence (Fig. 1). Intracellular bacteria are therefore in close contact with the hinge-like region of h-lamp-1, where target sites of the secreted bacterial protease are located.

\subsection{The IgAl protease is active in a low $p H$ environment}

To exert its action on h-lamp-1 the IgA1 protease has to be active under conditions described for late endosomal/lysosomal compartments. The most prominent characteristic of such vesicles is their low $\mathrm{pH}$. During phagosome maturation the $\mathrm{pH}$ drops from the $\mathrm{pH}$ of the extracellular milieu down to $\mathrm{pH}$ 4.5-5 [20,22]. Therefore, an intra-phagosomally active protease has to be $\mathrm{pH}$ tolerant. Since this has not previously been assessed for neisserial IgA1 protease, the purified enzyme was incubated with its cognate substrate human IgA globulins under varying $\mathrm{pH}$ conditions. Both at neutral and at low $\mathrm{pH}$, i.e. $\mathrm{pH} 4.5$, the typical cleavage products of the $\operatorname{IgA} 1$ globulin heavy chain were readily produced (Fig. 3). Compared to neutral $\mathrm{pH}$ conditions, there was no gross difference in the reactivity of the enzyme detectable. Intact IgA heavy chains visible on the gel after protease treatment reflected the presence of $\operatorname{IgA} 2$ molecules in the $\operatorname{IgA}$ preparation derived from human sputum.

\subsection{The IgA1 protease cleaves h-lamp-1 from epithelial cell lines}

In order to demonstrate that the neisserial protease is indeed capable of cleaving human lysosome-associated mem- brane proteins, we immunoprecipitated h-lamp-1 of $\left[{ }^{35} \mathrm{~S}\right]$ methionine-labelled cells and incubated the precipitate with purified gonococcal IgA1 protease. Since lamp proteins are post-translationally modified, we first determined the maturation kinetics of these glycosylated proteins in the different cell lines used. As is shown for myelomonocytic JOSK-M cells in Fig. 4A, newly synthesised lamp-1 matured from a 80-95 $\mathrm{kDa}$ form to a larger $\sim 150 \mathrm{kDa}$ form within $4 \mathrm{~h}$. This is in accordance with the kinetics found for the transport of newly synthesised lysosomal lamps in mouse macrophages and nor-

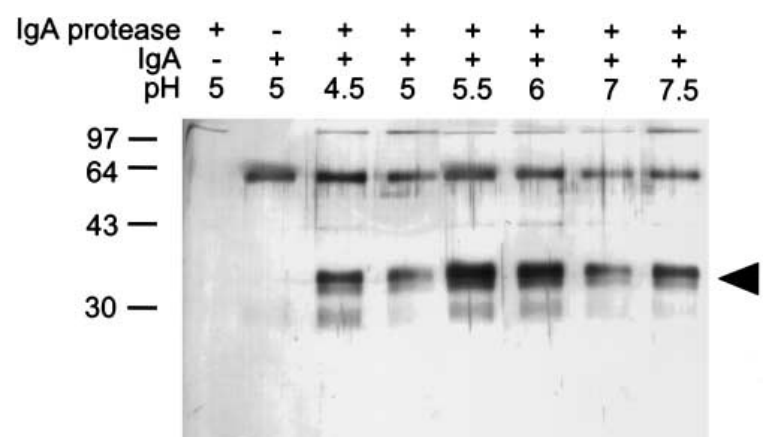

Fig. 3. The gonococcal IgA1 protease is active in a low $\mathrm{pH}$ environment. Human IgA1 molecules $(2 \mu \mathrm{g})$ were incubated with recombinant IgA1 protease of $N$. gonorrhoeae $(50 \mathrm{ng} / \mu \mathrm{l})$ or mock-incubated for $3 \mathrm{~h}$ at $37^{\circ} \mathrm{C}$ in buffers adjusted to different $\mathrm{pH}$ as indicated at the top of each lane. Samples were subsequently analysed by SDSPAGE and protein bands were visualised by silver staining. Cleaved fragments of the IgA1 globulin heavy chain (arrowhead) can be seen in all the preparations where IgAl protease has been added. 


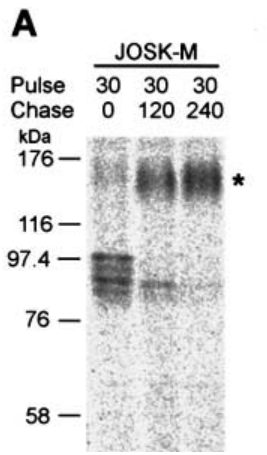

B

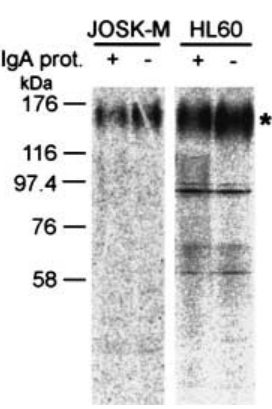

C

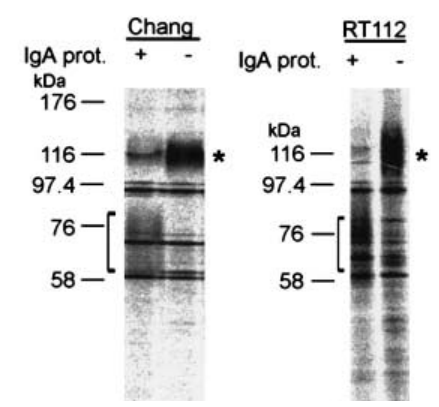

Fig. 4. $N$. gonorrhoeae IgA1 protease cleaves h-lamp-1 isolated from human epithelial cells in vitro. A: Human myelomonocytic JOSK-M cells were metabolically labelled with ${ }^{35}$ S]methionine for $30 \mathrm{~min}$ and h-lamp-1 was immunoprecipitated with $\alpha$-h-lamp-1 monoclonal antibodies (H4A3) after different chase periods as indicated. Immunoprecipitates were analysed by SDS-PAGE and visualised using a PhosphorImager. $4 \mathrm{~h}$ after the pulse, all labelled h-lamp-1 was found to be in the highly glycosylated mature form $(*)$. B: H-lamp-1 $(*)$ immunoprecipitated from human myelomonocytic JOSK-M cells and human myelocytic HL60 cells was incubated with recombinant gonococcal IgA1 protease or buffer for $4 \mathrm{~h}$ at $37^{\circ} \mathrm{C}$ as indicated. Fragments of the expected size (bar) were detectable neither by SDS PAGE nor by autoradiography. C: H-lamp$1\left(^{*}\right)$ immunoprecipitated with $\alpha$-h-lamp-1 monoclonal antibodies (H4A3) from metabolically labelled Chang epithelial cells and RT112 cells was incubated for $4 \mathrm{~h}$ at $37^{\circ} \mathrm{C}$ with recombinant gonococcal IgAl protease or buffer as indicated. Incubation with the protease results in degradation of h-lamp-1 into fragments of about $60-80 \mathrm{kDa}(\mathrm{bar})$.

mal rat kidney epithelioid cells [23]. Consequently, in subsequent experiments, cells were lysed to carry out immunoprecipitations $4 \mathrm{~h}$ after the $\left[{ }^{35} \mathrm{~S}\right]$ methionine pulse, in order to have the mature glycosylated forms of the proteins labelled. When the h-lamp-1 protein was isolated in this way from phagocytic human cells (JOSK-M, HL60) a protein of $\sim 150 \mathrm{kDa}$ was detected. The immunoprecipitated lamp appeared as a broad band after SDS-PAGE as previously reported [24,25]. No such band was visible in the control samples, where an isotype-matched antibody was used for precipitation. The isolated h-lamp-1 of phagocytic human cells was then incubated with recombinant $\mathrm{IgA} 1$ protease but cleavage products were not detectable (Fig. 4B).

Lamp-1 proteins immunoprecipitated from human epithelial cells (Chang, RT112) showed a different migration on SDS gels (Fig. 4C). It is known that different cell lines produce h-lamp glycoproteins of different apparent molecular weight, which is most likely due to differential glycosylation [25]. It appeared in our experiments that h-lamp proteins from epithelial cells were less glycosylated (size $\sim 115 \mathrm{kDa}$ ) as compared with the forms in phagocytic cells. Interestingly, when we incubated h-lamp-1 isolated from different human epithelial cell lines with the neisserial IgA1 protease, the immunoprecipitated band of about $115 \mathrm{kDa}$ vanished and cleavage products in the range of $60-80 \mathrm{kDa}$ appeared (Fig. 4C). The size of the cleavage products was consistent with the idea that the IgA1 protease cleaved within the hinge-like region located on the luminal side of h-lamp-1.

\subsection{Enhanced survival of IgAl protease-expressing gonococci in epithelial cells?}

To test whether the ability of the IgA1 protease to cleave phagosomal h-lamp-1 molecules could promote the intracellular accommodation and survival of $N$. gonorrhoeae, we investigated the survival of isogenic $\operatorname{IgA} 1$ protease mutants in Chang conjunctiva epithelial cells, a well-characterised in vitro infection model $[17,26]$, and RT112 bladder carcinoma cells [16]. For this purpose, we infected the cells with $N$. gonorrhoeae $\mathrm{N} 303\left(\mathrm{Opa}_{50}{ }^{+}, \mathrm{IgA} 1\right.$ protease $\left.^{+}\right)$or with $\mathrm{N} 876\left(\mathrm{Opa}_{50}{ }^{+}\right.$, IgA1 protease $\left.{ }^{-}\right)$at a bacteria:cell ratio of $30: 1$ for $6 \mathrm{~h}$ (Chang) or $12 \mathrm{~h}$ (RT112), respectively. After washing and an additional $1 \mathrm{~h}$ treatment with $50 \mu \mathrm{g} / \mathrm{ml}$ gentamicin, the cells were lysed with $1 \%$ saponin and suitable dilutions of the recovered bacteria were plated out. In none of these experiments were we able to reveal significant differences in the survival of IgA1 protease-positive versus IgA1 protease-negative gonococci (data not shown).

\section{Discussion}

Lysosome-associated membrane proteins (lamps) are known from several vertebrate species. Two distinct molecules, h-lamp-1 and h-lamp-2, have been characterised and sequenced in humans $[8,25]$. They are highly homologous to membrane proteins isolated from mouse, rat and chicken [27,28]. The major characteristic is their high content of $\mathrm{N}$ linked glycans, some of which are polylactosaminoglycans [25]. Whereas the polypeptide core of lamps accounts for about $40 \mathrm{kDa}$, the mature proteins have an apparent molecular weight $>100 \mathrm{kDa}$. Though lamp proteins seem to be conserved during evolution, their function is still unclear. It is speculated that they protect the membrane from the action of degradative enzymes within the lysosome by forming a carbohydrate coat on the luminal face of the lysosomal membrane $[27,28]$.

From several studies it has emerged that lamps are not only found in mature lysosomes but that they are characteristic constituents of phagosomal membranes [20,22]. Inert particles as well as live bacteria are found within lamp-positive vesicles shortly after their uptake by professional and non-professional phagocytes $[13,20]$. We show here that also $N$. gonorrhoeae co-localises with h-lamp proteins once inside epithelial or phagocytic cells (Fig. 2). As can be seen by immunofluorescence staining of infected cells, there is a tight association of the vesicle membrane and the enclosed gonococci. Given the small volume of the Neisseria-containing phagosome, proteins secreted by internalised gonococci should accumulate at relatively high concentrations. One of the best characterised secreted products of the pathogenic Neisseriae is the IgA1 protease, which is secreted via an autotransporter mechanism [2]. The enzyme seems to be expressed constitutively by $N$. gonorrhoeae MS11, but only at low levels [29]. In addition, our results demonstrate that the protease activity is not affected by low $\mathrm{pH}$ conditions. We therefore believe that the enzyme is 
expressed by internalised $N$. gonorrhoeae and that it is able to exert its activity in a maturing phagosome even at a nonphysiologic $\mathrm{pH}$. Since the lysosomal membrane protein $\mathrm{h}-$ lamp-1 is an abundant constituent of the phagosomal membrane and since it contains the $\operatorname{IgA} 1$ protease cleavage site consensus, we investigated if this protein could be a substrate of the neisserial enzyme. Our results demonstrate that the mature glycosylated form of h-lamp-1 derived from epithelial cells is susceptible to degradation by $\operatorname{IgA} 1$ protease. In addition, our data argue that in vitro the extent of glycosylation of the h-lamp-1 protein defines its sensitivity against degradation by the bacterial enzyme. Less glycosylated h-lamp-1 isolated from epithelial cells was readily degraded by IgA1 protease whereas the larger forms isolated from professional phagocytes were resistant against the activity of the enzyme. It is intriguing to speculate that in a rally of arms the pressure by pathogens and their secreted proteases has driven the evolution towards higher glycosylation and in this way towards more resistant h-lamp proteins in phagocytic cells.

Pathogenic Neisseria are known to interact with different cell types during the course of an infection [1]. Especially their attachment to and invasion of epithelial cells has been studied in great detail $[17,18]$. In addition, electron microscopic investigations have provided insights into the intracellular compartment inhabited by gonococci in epithelial cell lines and primary human cells [26,30]. Though in most cases the bacteria were found to reside in membrane-enclosed vesicles, several studies suggest an occasional escape of gonococci from the phagosome into the cytoplasm of epithelial cells ([30], Mosleh et al., submitted). Intracytosolic bacteria have been more often detected in human primary epithelial cells than in the standard infection models using permanent cell lines. It is therefore possible that phagosomal escape in native mucosal tissues is a natural event, and that $\operatorname{IgA} 1$ protease may facilitate the destruction of the phagosomal membrane.

We were not able to show a difference in the capability of wild-type and IgA1 protease-deficient $N$. gonorrhoeae MS11 to survive within Chang epithelial cells or RT112 using gentamicin assays (data not shown). This result is in contrast with a preliminary report suggesting that $\operatorname{IgA} 1$ protease is essential for the survival within epithelial cells [31]. Whether the difference of our result is due to the failure of this system to detect minute disparities in intracellular survival or to inherent differences between permanent epithelial cell lines and primary urethral or cervical cells must be the subject of future studies. For instance, the ratio of h-lamp-1 versus h-lamp-2 in the Neisseria-containing vacuole could determine the ability of gonococci to escape this compartment and this ratio could be different in primary and permanent cells. Given the possible new role for the gonococcal protease in the interaction with the human host, it seems interesting now to investigate if IgA1 proteases derived from other species like $N$. meningitidis or Haemophilus influenzae [4,32], Streptococcus pneumoniae [33] or IgA1 protease homologues with no reported function from other pathogenic microorganisms like SepA of Shigella flexneri [34] have the potential to interfere with human lysosomal/phagosomal membrane proteins, too.

Acknowledgements: We thank Ana-Clara Mißlitz for her expert technical help in preparing the IgA1 protease, Susanne Beck and Macquala Johnson for comments on the manuscript. We are grateful to Roland Barten for providing the kanamycin resistance construct. Part of this work has been supported by the Fonds der Chemischen Industrie.

\section{References}

[1] Meyer, T.F., Pohlner, J. and Van Putten, J.P.M. (1994) in: Bacterial Pathogenesis of Plants and Animals - Current Topics in Microbiology and Immunology (Dangl, D.L., Ed.) pp. 283-317, Springer, Berlin.

[2] Pohlner, J., Halter, R., Beyreuther, K. and Meyer, T.F. (1987) Nature 325, 458-462.

[3] Plaut, A.G., Gilbert, J., Artenstein, M.S. and Carpa, J.D. (1975) Science 190, 1103-1105.

[4] Cooper, M.D., McGee, Z.A., Mulks, M.H., Koomey, J.M. and Hindman, T.L. (1984) J. Infect. Dis. 150, 737-744.

[5] Kilian, M., Mestecky, J. and Russell, M.W. (1988) Microbiol. Rev. 52, 296-303.

[6] Kilian, M., Reinholdt, J., Lomholt, H., Poulsen, K. and Frandsen, E.V.G. (1996) Acta Pathol. Microbiol. Immunol. Scand. 104, 321-338.

[7] Mulks, M.H. and Knapp, J.S. (1987) Infect. Immun. 55, 931-936.

[8] Fukuda, M., Viitala, J., Matteson, J. and Carlsson, S.R. (1988) J. Biol. Chem. 263, 18920-18928.

[9] Liu, Y.-S.V., Low, T.L.K., Infante, A. and Putnam, F.W. (1976) Science 193, 1017-1020.

[10] Pohlner, J., Klauser, T., Kuttler, E. and Halter, R. (1992) Bio/ Technology 10, 799-804.

[11] Pohlner, J., Krämer, J. and Meyer, T.F. (1993) Gene 130, 121126.

[12] Binscheck, T., Bartels, F., Bergel, H., Bigalke, H., Yamasaki, S., Hayashi, T. and Pohlner, J. (1995) J. Biol. Chem. 270, 1770 1774.

[13] Garcia-Del Portillo, F. and Finlay, B.B. (1995) Trends Microbiol. 3, 373-380.

[14] Clemens, D.L. (1996) Trends Microbiol. 4, 113-118.

[15] Russell, D.G. (1995) Trends Cell Biol. 5, 125-128.

[16] Boxberger, H.J. and Meyer, T.F. (1994) Biol. Cell 82, 109-119.

[17] Makino, S., Van Putten, J.P.M. and Meyer, T.F. (1991) EMBO J. 10, 1307-1315.

[18] Kupsch, E.-M., Knepper, B., Kuroki, T., Heuer, I. and Meyer, T.F. (1994) EMBO J. 12, 641-650.

[19] Ryll, R.R., Rudel, T., Scheuerpflug, I., Barten, R. and Meyer, T.F. (1997) Mol. Microbiol. (in press).

[20] Desjardins, M., Huber, L.A., Parton, R.G. and Griffiths, G. (1994) J. Cell Biol. 124, 677-688.

[21] Fukuda, M. (1991) J. Biol. Chem. 266, 21327-21330.

[22] Berón, W., Alvarez-Dominguez, C., Mayorga, L. and Stahl, P.D. (1995) Trends Cell Biol. 5, 100-104.

[23] Green, S.A., Zimmer, K.P., Griffiths, G. and Mellman, I. (1987) J. Cell Biol. 105, 1227-1240.

[24] Mane, S.M., Marzella, L., Bainton, D.F., Holt, V.K., Cha, Y., Hildreth, J.E. and August, J.T. (1989) Arch. Biochem. Biophys. 268, 360-378.

[25] Carlsson, S.R., Roth, J., Piller, F. and Fukuda, M. (1988) J. Biol. Chem. 263, 18911-18919.

[26] Weel, J.F.L. and Van Putten, J.P.M. (1991) Res. Microbiol. 142, 985-993.

[27] Hunziker, W. and Geuze, H.J. (1996) BioEssays 18, 379-389.

[28] Peters, C. and von Figura, K. (1994) FEBS Lett. 346, 108-114.

[29] Meyer, T.F., Halter, R. and Pohlner, J.(1987) in: Recent Advances in Mucosal Immunology, Part B (Mestecky, J., McGhee, J.R., Bienenstock, J. and Orga, P.L., Eds.) pp. 1271-1281, Plenum, New York.

[30] Apicella, M.A., Ketterer, M., Lee, F.K.N., Zhou, D., Rice, P.A. and Blake, M.S. (1996) J. Infect. Dis. 173, 636-646.

[31] Lin, L., Ayala, P., Mulks, M., Enns, C. and So, M. (1996) in: Abstracts of the Tenth International Pathogenic Neisseria Conference (Zollinger, W.D., Frasch, C.E. and Deal, C.D., Eds.) p. 293, Baltimore.

[32] Lomholt, H., Poulsen, K. and Kilian, M. (1995) Mol. Microbiol. $15,495-506$.

[33] Kilian, M., Mestecky, J. and Schrohenloher, R.E. (1979) Infect. Immun. 26, 143-149.

[34] Benjelloun-Touimi, Z., Sansonetti, P.J. and Parsot, C. (1995) Mol. Microbiol. 17, 123-135. 